\title{
THE MOTIVATIONAL FACTORS ON USING VIRTUAL HOTEL OPERATORS' ACCOMMODATION AMONG TOURISTS IN CEBU CITY, PHILIPPINES
}

\author{
James G. Esguerra ${ }^{1}$ and Mariae Khrisna Baring Arreza ${ }^{2}$ \\ Cebu Institute of Technology- University, \\ Cebu City, Philippines \\ jamesesguerra495@gmail.com ${ }^{1}$ \\ mariae_arreza@outlook.com²
}

\begin{abstract}
This study looked into the influence of the motivational factors among foreign and local tourists who availed of the VHO-partnered hotels in Cebu City. The study utilized a descriptive-correlational design to look into the level of influence on the factors of (a) ease of navigation, (b) opportunity to earn points and rewards, (c) availability of affordable pricing, and (d) simplicity of reservation process and varied mode of payments. Three hundred thirty-nine (339) both local and foreign tourists participated in this study. The results showed that the level of influence on the motivational factors is of the highest degree, while the difference between foreign tourists traveling for business and leisure purposes on the motivational factors show no significant difference. On one hand, local tourists traveling for business and leisure revealed a significant difference. Furthermore, the comparison of the level of influence between local and foreign tourists, in general, showed a noteworthy significant difference. Further study of VHO in a different setting is recommended to get a better generalization on the VHO topic.
\end{abstract}

Keywords: Foreign Tourists, Local Tourists, Motivational Factors, Virtual Hotel Operators

\section{INTRODUCTION}

The fourth industrial revolution has brought changes that lead to progress in our society all over the world. Innovations brought by the dawn of $4^{\text {th }}$ I.R. have provided opportunities to many industries to improve their business models to ride on the competitive business arena. Today's economy is moving toward the fourth industrial revolution (FIR), which is defined by the adoption of technologies such as cyber-physical systems, the internet of things, big data, artificial intelligence, and robotics. Globally, there has been a lot of discussion about the impact of the FIR on all industries, including hospitality and tourism (Osei et al., 2020). 
Hospitality is one of the sectors in the tourism industry that is no exemption to the changes that are taking place. The tourism industry in the Philippines is at a fast-growing rate that results in the convenience of a diverse range of lodging options available to tourists. From the standpoint of the consumer, the ICT economy has implied new opportunities, particularly in terms of cost comparisons and the ability to identify the "best" accommodation and the "hippest" locations. The "most popular" attraction is a restaurant. Platforms have also shaped consumer cultures because they streamline opinion, tastes, preferences, and interests through propositions of desirable social form, encouraging, if not demanding, that users evaluate and judge (Gossling, 2017). The hospitality sector has become the hub of many advances in business practices and technological integration. Technology has now become an integral part of the operations in many hotels across the globe. The creation of sophisticated information and communication technologies (ICTs) together with the growth of the Internet has served as a forum for promoting engagement with and among customers, as well as the forming of brand communities (Muñiz Jr and Schau, 2006).

Srovnalková et al., (2020) mentioned that the innovation that created the concept of sharing economy is present in various businesses and it has resulted in a significant impact on the tourism and the hospitality industry. The internet has transformed the tourism industry by converting traditional tourism channels into online channels, the sharing economy has amassed a collective number of accommodation businesses in the hospitality industry. As a result, developing an effective hotel management strategy is critical Technology has made consumers highly knowledgeable in their purchases. They can also compare facilities across numerous hotel brands and book online rather than over the phone. Traditional businesses are compellingly disrupted because of rapid digitalization. Consumers, manufacturers, and their networks have built a stronger bond and accessibility. Some companies undergo exponential growth as a result of this breakthrough. According to Oskam \& Boswijk, ( 2016) the ease of using an app on one's phone and the capacity to book a room without providing credit card details has made it more appealing to consumers. When using Apple Pay or other similar apps, Airbnb and VHO have access to other reviewers' comments, which can influence customer buying decisions (Teck \& Karuppiah, 2020). Airbnb and other companies using similar technologies have carved out a position for themselves by utilizing all that a hotel guest needs. VHO has plans to magnify their presence and linger to develop at an exceptional rate. A shift in consumer attitude has resulted in app-based booking. Financial and personal achievement prospects VHO and similar platforms would have been even more difficult if not for technology (Douglas, 2018). The demand for a better service is becoming an advocacy and at the same time a burden for many hotel operators. With this reality, many are seeking out ways to improve their services to stay competitive in the business arena by innovating processes or integrating technology in their services. The new concept of business in the hotel sectors such as the sharing economy is taking its place in the competition. One of the many notable innovations in the hotel accommodation sector is the emergence of virtual hotel operators. In some Asian countries such as Indonesia, this business concept took its place in 2015 (Wiastuti \& Susilowardhani,2016). 
VHO and other related technologies are multibillion-dollar markets in Southeast Asia and have tremendous market potential and increasing influence (Ahmad et al., 2018; Wiastuti \& Susilowardhani, 2016). The Virtual Hotel Operator model was born out of an increase in demand for clean and low-cost lodging. RedDoorz, Oyo rooms, Nida rooms, and Zen rooms are the most well-known and perceptible brands in Metro Cebu. VHO caters to the budget traveler, offering an inventory of affordable lodging. It is definite in an industry with so many variables that hoteliers must boost technical creativity because this can result in most tourists using VHOs and other similar platforms.

The booming of budget travel has been a big opportunity for small to midrange hotel accommodations. Tourists' behaviors are now influenced by many things such as technology and other social factors that shape their perception of the value of a hotel accommodation, and now seen more than just what is usually offered. Tourists are aware of product or service developments to the point that they may affect their buying decision (Hjalager, 2010). Traveling has now become more personalized; it can now be arranged by the tourists themselves through the use of technology, through the use of booking applications (booking.com, trivago, etc.). Virtual hotel operators took advantage of these changes and created a platform where they can reach prospective guests from different places across the world. Furthermore, the rising demand for clean and budget-friendly accommodation brought the VHO into its position in the market due to its partnership with this kind of hotel. Virtual Hotel Operators such as OYO, Zen Rooms, and Red Doorz are now present in Cebu City, Philippines-in particular. There are quite several small to midrange hotels that partnered with VHOs. The digital market has increased its presence and its chance for potential guests due to the wide coverage of the digital world. Avili (2016) explained that VHOs do not own hotels; they are the same as the concept of uber taxis. Virtual Hotel operators take several rooms in each of the qualified hotels and rebrand them into VHO. Each VHO-has its own criteria requirement when considering its partner hotels. The dawn of VHO in Cebu City is still at an early stage, however, interest in the use of this platform among tourists has become more popular over time. Sciarelli et al., (2018) explained that customer behavior is often a challenge and an opportunity for all kinds of businesses. The tourism industry is an ever-dynamic industry that thrives to make the tourists' experience better. The industry has been a leader in ICT and digital growth, which resulted in the evolution of the value chain and business-to-consumer relationships. The increasing amount of information available has paradoxically resulted in an "informative syndrome," which makes these relationships more complicated and complex at times The implementation of new ICT can increase efficiency in tourism businesses (Blake, Sinclair, and Soria, 2006). According to Lopez (2020), there has been an increase in the number of digital natives with location-independent living and working styles in recent years. In the mainstream press, the emergence of digital nomads has been attributed to a desire to escape the "rat race" of urban life. Economic development depends on the success of small companies. The need to nurture a competitive advantage is a persistent obstacle for small business owners (Bressler, 2012). Digitalization allows businesses to develop well beyond their 
traditional markets. These businesses grow at the same rate as the well-recognized brands in the industry. The results are stronger, quicker, and less expensive (Teng et al., 2020; Oskam \& Boswijk, 2016). In the hospitality industry, VHOs have many potentials, particularly in terms of increasing sales and quality. A partnership with a VHO and similar technology may be an option only after a thorough examination of the overall environment (Wiastuti \& Susilowardhani, 2016; Koutroumanis, 2011). Business model innovation in the hotel sector affects the perspectives of the guests when considering accommodation. Many process advances have relied on information and communication technology (ICT) in recent decades, and it has sparked a major strand of research with its agendas and institutions (Buhalis \& Law, 2008).

Tourists come in with different purposes, and two of the most popular traveling reasons are leisure and business. Each purpose for travel comes with different needs in terms of the travel arrangements and the accommodation. However, whether for business or leisure travel, common considerations among tourists may include convenience, budget, and cleanliness and VHOs provide such qualities of accommodation as they provide varying choices of the rooms and prices that may suit the budget of the tourists which, therefore, allowing them to serve both business and leisure travelers. A few researchers focused on the motivational factors that influence tourists to avail the VHO affiliated hotels' booking system. There have been limited studies concerned with how tourists perceived the VHO booking system. Therefore, this research intends to look into the perception of both foreign and domestic tourists on the motivational factors that influence them to avail themselves of VHO affiliated hotels in Cebu City. The specific objectives of this research are (a) identify the profile of the tourists according to the types of travelers and types of travel purposes, (b) evaluate the level of influence of the motivational factors that lead tourists traveling for business and leisure in Cebu City to avail VHO affiliated hotels and; (c) differentiate the perception towards VHO utilization between foreign tourists and local tourists in Cebu City.

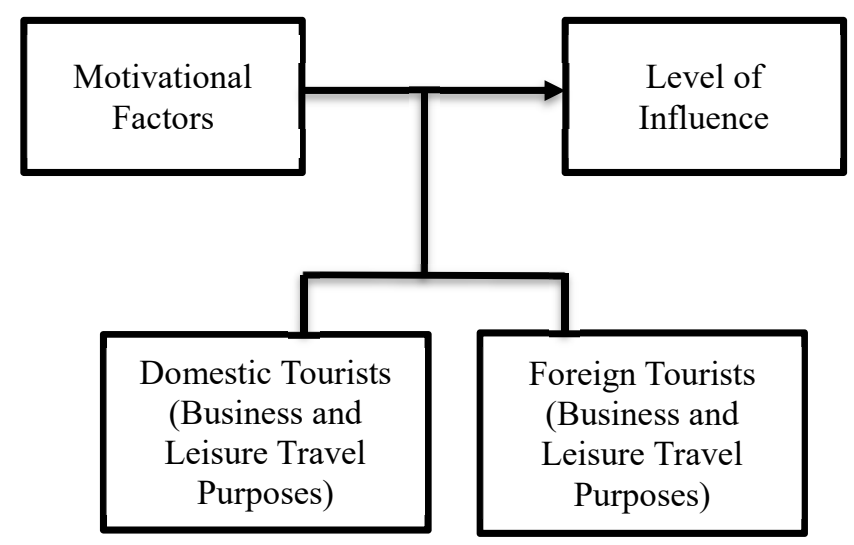

Figure. 1 Conceptual Framework of the Study 
Figure 1 presents the conceptual framework of the study, the researchers identified factors as key indicators to measure the motivational factors that led the in-house guests which are domestic and foreign tourists to avail of the VHO affiliated hotels. The identified factors are ease of navigation, as VHO generally rely on technology through platform through a webpage or can be accessed through the use of mobile phone, when consumers believe that technology is simple to use and learn, they are more likely to adopt it, especially if it is supported by a userfriendly interface, and how to use it quickly (Ontiveros et al., 2018). Another factor that was looked into is the opportunity to earn points, rewards; avail coupons; discounts, Büyükdağ et al., (2020) concluded that pricing is one of the most important marketing tools that can direct the feelings, perceptions, and behaviors of the consumers. Therefore, consumers' reactions to price promotion are important in terms of pricing. Because specific discount pattern in terms of price promotion scenarios for both cognitive and emotional perceptions of consumers is a vital element for the sustainability of products and companies. The effect of different specific discount patterns in terms of price promotion scenarios on perceived price attractiveness and purchase intention was investigated in their study, and the results revealed that price promotion scenarios have a significant impact on perceived price attractiveness and purchase intention. Availability of affordable pricing, was also one of the key factors that were considered, according to Kim, (2019) the most commonly used marketing/retail tool is price promotion. acquiring new clients for long-term service providers. Because retailers lower their prices, the products become more accessible to all buyers (Chen et al., as cited by Büyükdağ et al., 2020). Availability of desired product, guests always have expectations in mind when it comes to what they want for their rooms, it may depend on their budget or their comfort. Oftentimes, they would prefer several options to choose from before they make proper decisions. According to Andrews et al., (2016), if a person starts the process by debating whether or not to buy at all, a large selection is likely to be appealing and make him or her more likely to decide in favor of purchasing. If, on the other hand, a person begins by selecting a favorite from a variety of options and then decides whether or not to buy, a large selection makes the task more difficult and reduces the likelihood of purchasing.

Provision of detailed information was also looked into in this study and according to Dharmesti and Nugroho, (2013) online consumers with various motivations will respond to website design in various ways, and consumer motivation influences information processing patterns and emotions. Furthermore, they stated that a good website has a good organization in which consumers will find it easy to access the desired information about the product. Good website design is a neat screen appearance, clear information path, and quick information loading, and availability of different modes of payment other than the credit card. In the Philippine context, despite the recent growth of the electronic payment (epayment) industry, cash transactions continue to dominate in the country. One factor influencing this slow growth rate is the country's small bank population ( Raon, et al., 2021). 


\section{METHODOLOGY}

This study utilized a quantitative method specifically a descriptive correlational design. A researcher-made questionnaire to gather data on the profile of the respondents and the level of influence of the motivational factors in utilizing VHOs among tourists checked in VHO partnered hotels; and conducted in the selected 40 VHO partner hotels in Cebu City. The respondents of this study were in-house guests of the VHO hotels at the time of the conduct of the study. The selection of participants was based on the following criteria: (a) must be a tourist checked-in a VHO partner hotel in Cebu City, (b) must have utilized the VHO booking system, (c) must be willing to participate and give voluntary consent. 339 tourists participated in this study, Domestic - 209; Foreign - 130. The instrument centered on the motivational factors of the VHO accommodation system in terms of ease of (a) navigation, (b) opportunity to earn points and rewards, (c) availability of affordable pricing, (d) simplicity of reservation process, and (e) varied mode of payments. The instrument underwent pilot testing activity with 30 participants which resulted in a Cronbach alpha value of 0.7 which is reliable for administration. The gathered were statistically treated using frequency count and percentage for the profile of respondents, weighted mean for the level of influence of the motivational factor, and Mann- Whitney U tests were done to look into the differences of the level of influence between foreign and local tourists and difference on the influence level between tourists traveling for leisure and business purposes.

\section{RESULTS AND DISCUSSION}

Table 1. Profile of the Respondents

\begin{tabular}{lllll}
\hline Types of Travelers & \multicolumn{3}{c}{ Type of Travel Purposes } \\
\hline & $\begin{array}{l}\text { Business } \\
(\mathbf{n = 1 2 7 )}\end{array}$ & $\begin{array}{l}\text { Leisure } \\
(\mathbf{n = 2 1 2})\end{array}$ & \\
& Frequency & Percentage & Frequency & Percentage \\
\hline Domestic & 89 & $70.07 \%$ & 120 & $56.60 \%$ \\
Foreign & 38 & $29.92 \%$ & 92 & $43.39 \%$ \\
\hline
\end{tabular}

n=339, Domestic $-209 ;$ Foreign -130

As presented in table 1, participants were clustered into domestic and foreign travelers. On the one hand, among, domestic travelers, travel for the reasons of leisure is higher by $13.47 \%$ compared to business purposes traveling. On the other hand, foreigners traveling for business purposes are lower than those traveling for leisure purposes. In this study, the data suggest that traveling for leisure purposes is more popular among the two groups of participants combined. 
Table 2. Level of influence of the motivational factors of VHO accommodation booking

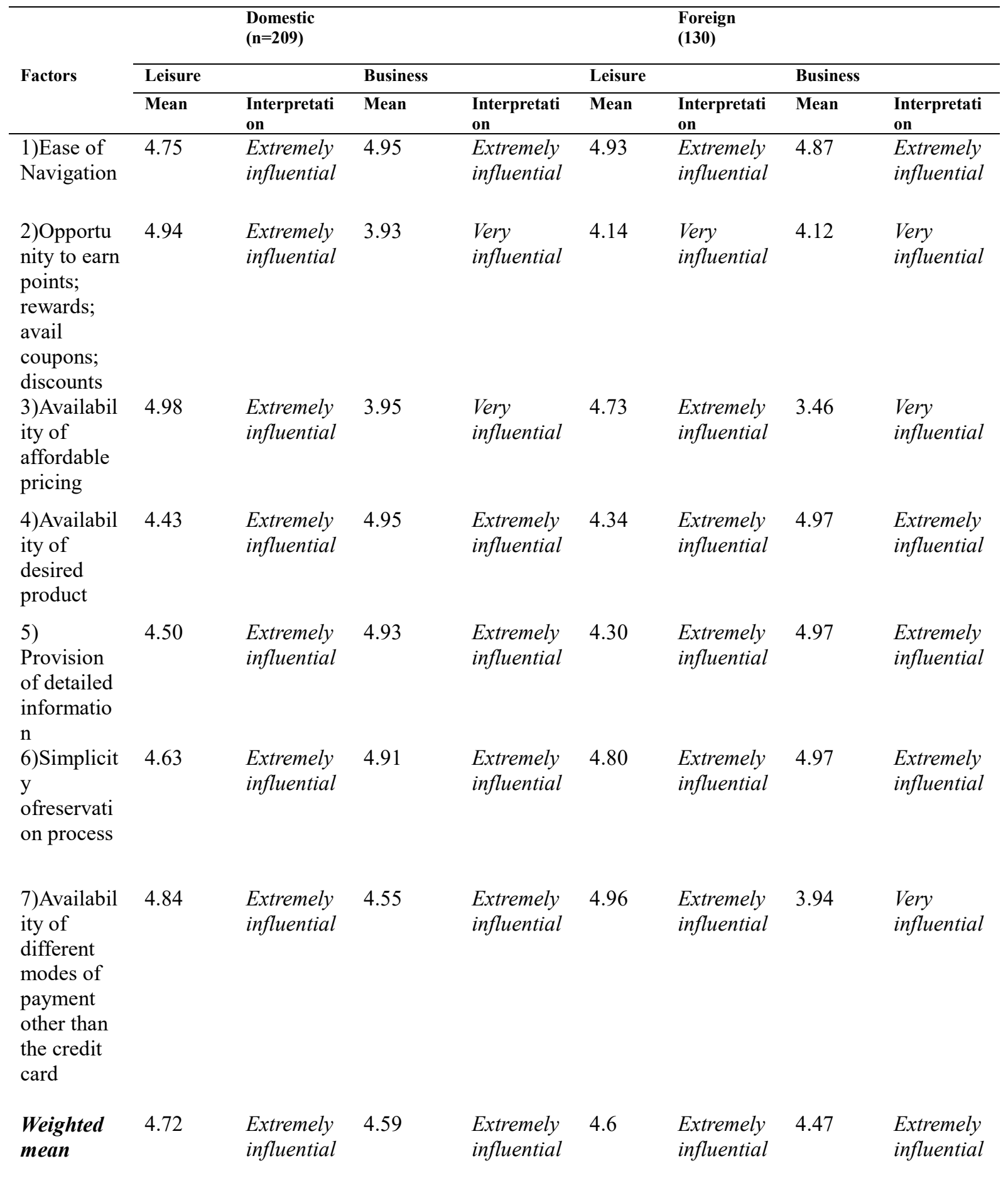

Legend: Extremely influential( 4.20-5.00,) very influential (3.40-4.19), somewhat influential (2.60-3.39), slightly influential (1.80-2.59), not at all influential (1.001.79) 
The table indicates that with the domestic group who are traveling for leisure purposes, the level of influence of the motivational factors to utilize the online VHO accommodation booking system has the general weighted mean of 4.72; this means that for this group of domestic travelers, booking through online VHO is extremely influential. On one hand, domestic travelers on business travel have the general weighted mean of 4.59 which is similarly interpreted as extremely influential. The results imply that domestic travelers regardless of their reasons for traveling, are highly motivated to utilize the online VHO accommodation booking system on the factors of convenience, opportunity to earn points, availability and affordability of pricing, desired product, detailed information, simplicity of the process and the different mode of payments available generally influence the domestic traveler's decision to use the online VHO accommodation booking system as indicated on the mean scores each of the motivational factors. In the studies of Srovnalíková et al., (2020) and Richard (2017), they both mentioned that guests are becoming more diverse in terms of demographics and expectations. Online hotel reservations are preferred by guests because of their ease, convenience, access to a varied range of product inventory, faster processing. Thus, it provides an over better smooth overall transaction.

Meanwhile, foreign travelers on leisure travel have a general weighted mean of 4.6 which means that the factors presented in the table above extremely influenced the decision of this group to use the online VHO accommodation booking system. As for the foreigners on business travel, the general weighted mean is 3.9, which is interpreted as very influential. The data indicates there is a slight difference between leisure and business travelers. On the factors of opportunity of earning points, availability and affordability of pricing, and different modes of payments, the mean scores are 3.46, 3.49 4.12 respectively, which are below the highest mean range scores. The results however imply that generally, the two groups of foreign travelers are indeed influenced by the aforementioned factors that motivate them to utilize the booking system regardless of the slight score differences.

Table 3. Difference between Business vs Leisure Foreign Travelers

\begin{tabular}{ll}
\hline Mann- Whitney U & 85596.500 \\
Wilcoxon W & 293931.500 \\
Z & -0.064 \\
Asymp. Sig. (2- tailed) & 0.949 \\
\hline
\end{tabular}

A Mann-Whitney test was done to test significant differences in the level of influence on the factors to utilize VHO booking between foreign travelers for business and leisure purposes. The p-value of 0.0949 shows no significant difference between the two groups of foreign travelers. The result implies that in terms of the motivation to utilize the VHO booking system, the two foreign tourists (traveling for business and leisure) may have the same viewpoint on the motivational factors presented in this study. 
Table 4. Difference between Business vs Leisure Domestic Travelers

\begin{tabular}{ll}
\hline Mann- Whitney U & 247969.500 \\
Wilcoxon W & 442345.500 \\
$Z$ & -2.367 \\
Asymp. Sig. (2- tailed) & 0.018 \\
\hline
\end{tabular}

The data reveal that there was a significant difference between the domestic travelers on business and leisure on the factors that influence to utilize VHO booking system. This means that the two groups of domestic travelers have a different perception of the 7 factors presented. This could also imply that at a certain point domestic business travelers and domestic leisure travelers vary considering the purpose of their travels.

Table 5. Difference between Domestic vs Foreign travelers

\begin{tabular}{ll} 
Mann- Whitney U & 608350.500 \\
Wilcoxon W & 1023766.50 \\
Z & -4.683 \\
Asymp. Sig. (2- tailed) & 0.000 \\
\hline
\end{tabular}

Table 5 presents the result of the test between domestic and foreign travelers in general. The data reveal the p-value of 0.000 which is statistically highly significant. This means that the level of influence of the motivational factors to utilize the VHO booking system among the two groups of travelers significantly differ. It can be inferred that these two groups of travelers may have different viewpoints on what to consider in booking accommodation based on the purposes of their travels. Moreover, the results can be attributed to the difference in expectations and experiences in the utilization of the VHO booking system.

\section{DISCUSSION}

The study focuses on the motivational factors that influenced both domestic and foreign tourists to avail of the VHO affiliated hotels. The findings present that in this study, in terms of representation there were more domestic and foreign tourists on leisure travel availed VHO affiliated hotels compared to those traveling for business purposes. The motivational factors that influenced both domestic and foreign tourists to book in VHO affiliated were observed to be extremely influential, this means that both tourists traveling for different purposes (business or leisure) shows a positive perception towards the motivational factors as indicated in this study. On the comparison of the perception of the in-house foreign tourists traveling for business versus the foreign tourists traveling for leisure, it was observed that there was no significant difference in their perception of the motivational factors that influenced them. This may imply that both groups of foreign tourists seek the same value on what they find important in considering booking in VHO affiliated hotels. A similar comparison was also done with in-house guests coming from 
domestic tourists, the results garnered a significant difference in the perception on the motivational factors that influence domestic tourists traveling for business and leisure purposes, the results suggest that their perceived value may at some point different from one another which can be attributed to their purpose of travel. The study also compared domestic versus foreign tourists' perception the motivation factors that influenced tourists to avail themselves VHO accommodations, the results show a highly significant difference between the two groups of tourists, this may imply that the two groups have different perceptions on the motivational factors that affect their level of influence.

As revealed in the results of the study, tourists (both domestic and foreign) find the ease of navigation to be influential in choosing to use VHO affiliated hotels' booking systems. It was also seen the opportunity to earn points, rewards, and discounts were also observed to be an influential factor. Tourists were also after affordable pricing and the desired product to be available in VHO affiliate hotels. It was also observed that availability of information, simplicity of reservation is also considered by the participants to be influential. Lastly, modes of payment other than credit cards were also seen to be influential to their choice to pursue VHO hotels. In general, the study shows that the above motivational factors were indeed influential among the participants of the study, and as a practical implication in the field of hospitality, VHO is an emerging business model in the hotel operations, it may provide opportunities to small and medium-size hotels which have different target markets. It is important to look into how the above-measured factors can help hotels in their operations that will lead to a better guests' experience.

\section{CONCLUSION}

The study concluded that in general, the factors that were assessed in this study influenced the two groups of respondents to a high degree. The manifestation of the higher influence of the motivational factors denotes that the respondents are leaning towards the Virtual Hotel Operators and their platform booking system. This behavior towards the use of the VHO booking system can also be attributed to the system's advantages as it provides more value, a wide range of competitive prices, and is more accessible through a phone application. The salient features of the VHO booking application contribute to the overall influence of the users. Looking at the way tourists respond to this system; surely provides opportunities for many budget-friendly hotels to reach more prospective guests. The dawn of technology makes tourists more self-sufficient when it comes to traveling, the use of technology is within their reach which makes it easier for them to organize or make arrangements with their travel and bookings. This self-sufficiency behavior should be considered and be taken into account by hotel operators not only to those in partnership with VHO but also those who are operating without VHO partners. Small and medium-sized hotels should seize the opportunity to better serve their prospective guests, and this can only be done by adopting new concepts to be able 
to ride on the fast pace of the 4th Industrial revolution. The results of this study constitute only samples of a single city. There is a need for additional researches to obtain a much better and deeper understanding of the behavior and motivation of tourists to utilize the VHO booking system and avail accommodations from VHO partners. Widening the scope of the sample participants of the study by including other major cities on the Island of Cebu will generate a better generalization.

\section{REFERENCES}

Ahmad, A., Idris, N. A., \& Ibrahim, Y. A. (2018). Critical success factors and customer satisfaction in Budget Hotels: A case study from Malaysia. Journal of Tourism \& Hospitality, 07(02). https://doi.org/10.4172/21670269.1000346

Andrews, E. L., Gao, L., \& Simonson, I. (2016, November 9). Are consumers turned off by too many choices? not yet. Stanford Graduate School of Business. Retrieved December 28, 2021, from https://www.gsb.stanford.edu/insights/are-consumers-turned-too-manychoices-not-yet

Avili, Kaneswaren, (2016)," Virtual hotel operator receives RM16.76mil injection', retrieved from http://www.thestar.com.my/metro/smebiz/news/20 hotel -rooms-fundingnext-stage-growth/

Blake, A., Sinclair, M. T., \& Soria, J. A. C. (2006). Tourism productivity: evidence from the United Kingdom. Annals of Tourism Research, 33(4), 1099-1120.

Bressler, M. S. (2012). How small businesses master the art of competition ... AABRI. Retrieved December 24, 2021, from https://aabri.com/manuscripts/121156.pdf

Büyükdağ, N., Soysal, A. N., \& Kitapci Olgun. (2020). The effect of specific discount pattern in terms of price promotions on perceived price attractiveness and purchase intention: An experimental research. Journal of Retailing and Consumer Services, 55, 102112. https://doi.org/10.1016/j.jretconser.2020.102112

Dharmesti, M. D. D., \& Nugroho, S. S. (2013). The Antecedents of online customer satisfaction and customer loyalty. Journal of Business and Retail Management Research, Vol. 7(2), 1-12. https://doi.org/10.24052/JBRMR/123

Douglas, E. A. (2018). "Airbnb's Effect on the Hospitality Industry". The Copula Scholarship at Gettysburg College. Retrieved December 28, 2021, from https://cupola.gettysburg.edu/student_scholarship/608 
Gossling, S. ( $€$ 2017). Internet technologies, tourism, and sustainability: An exploratory review. Journal of Sustainable Tourism, 25(7), 1024-1041. https://doi.org/10.1080/09669582.2015.1122017

Hjalager, A. M. (2010). A review of innovation research in tourism. Tourism Management, 31(1), 1-12.

Jensen Schau, H., \& Muñiz Jr, A. M. (2006). A tale of tales: the Apple Newton narratives. Journal of Strategic Marketing, 14(1), 19-33.

Kim, J. (2019). The impact of different price promotions on customer retention. Journal of Retailing and Consumer Services, 46, 95-102. https://doi.org/10.1016/j.jretconser.2017.10.007

Koutroumanis, D. A. (2011). Technology's Effect on Hotels and Restaurants: Building a Strategic Competitive Advantage. Journal of Applied Business and Economics, 12(1), 72-80. https://doi.org/www.nabusinesspress.com/JABE/KoutroumanisWeb.pdf

Lopez-Cordova, E. (2020). Digital Platforms and the Demand for International Tourism Services. The World Bank.

Ontiveros-Robles, E., Melin, P., \& Castillo, O. (2018). Comparative analysis of noise robustness of type 2 fuzzy logic controllers. Kybernetika, 175-201. https://doi.org/10.14736/kyb-2018-1-0175

Osei, B. A., Ragavan, N. A., \& Mensah, H. K. (2020). Prospects of the fourth industrial revolution for the hospitality industry: A literature review. Journal of Hospitality and Tourism Technology, 11(3), 479-494. https://doi.org/10.1108/jhtt-08-2019-0107

Oskam, J., \& Boswijk, A. (2016). Airbnb: the future of networked hospitality businesses. Journal of tourism futures.

Raon, C. J., De Leon, M. V., \& Dui, R. (2004). Adoption of e-payment systems in the Philippines. Jurnal ILMU KOMUNIKASI, 18(1), 123-134. https://doi.org/10.24002/jik.v18i1.3197

Richard, B. (2017). Hotel chains: survival strategies for a dynamic future. Journal of Tourism Futures, 3(1), 56-65. https://doi.org/10.1108/jtf-06-2016-0018

Sciarelli, F, Della Corte, V., \& Del Gaudio, G. (2018). The evolution of tourism in the digital era: The case of a tourism destination. Sinergie Italian Journal of Management, (105), 179-199. https://doi.org/10.7433/s105.2018.09

Srovnalíková, P., Semionovaitè, E., Baranskaitè, E., \& Labanauskaitė, D. (2020). Evaluation of the Impact of Sharing Economy on Hotel Business. Journal Of Tourism And Services, 11(20), 150-169. https://doi.org/10.29036/jots.v11i20.145 
Teck, T., \& Karuppiah, N. (2020). Operation Strategy as a Competitive Advantage in Hotel Industry. International Business Research, 13(2), 35. https://doi.org/10.5539/ibr.v13n2p35

Teng, Y.-M., Wu, K.-S., \& Chou, C.-Y. (2020). Price or Convenience: What Is More Important for Online and Offline Bookings? A Study of a FiveStar Resort Hotel in Taiwan. Sustainability, 12(10), 3972. https://doi.org/10.3390/su12103972

Wiastuti, R., \& Susilowardhani, E. (2016). Virtual Hotel Operator; Is it Disruption for Hotel Industry?. Jurnal Hospitality Dan Pariwisata, 2(2), 201-215. https://doi.org/10.30813/.v2i2.905 